\title{
ANALISA DAMPAK KETERLAMBATAN MUTASI TERHADAP KINERJA PELAUT
}

\author{
Renny Hermawati ${ }^{1^{*}}$, Ali Khamdilah ${ }^{2^{* * *}}$ \\ ${ }^{1}$ Program Studi Nautika, UNIMAR AMNI Semarang \\ Jl. Soekarno - Hatta 180 Semarang \\ ${ }^{2}$ Program Studi Teknika - Politeknik Bumi Akpelni \\ Jln. Pawiyatan Luhur II/17 Bendan Dhuwur Semarang \\ Email : rennyhermawati36@gmail.com \\ **Email : alikhamdilah@gmail.com
}

\begin{abstract}
Abstrak
Pelaut adalah sebutan untuk orang yang bekerja diatas kapal. Dalam bekerja, seorang pelaut dituntut untuk menyelesaikan kontrak kerja sesuai dengan yang tertuang dalam Perjanjian Kerja Laut (PKL). PKL dinyatakan syah apabila ditandatangani oleh pelaut yang bersangkutan, pemilik kapal serta disyahkan oleh Syahbandar. Ketika seorang pelaut menyelesaikan masa kontrak yang telah disepakati dan tertuang dalam PKL, selanjutnya pelaut tersebut berhak mendapatkan cuti. Akan tetapi berdasarkan fenomena yang ada dilapangan, ditemukan pelaut yang tetap bekerja diatas kapal sekalipun telah selesai masa kontraknya.Untuk mengetahui efektifitas kinerja yang dihasilkan oleh pelaut yang mengalami over kontrak, dilakukanlah analisa terhadap dampak keterlambatan mutasi on dan mutasi off terhadap pelaut dengan menggunakan media SWOT Analysis. Berdasarkan Hasil analisis yang dilakukan diketahui bahwa kelemahan dan hambatan yang akan dialami oleh perusahaan jauh lebih banyak dibandingkan dengan kekuatan dan tantangan/peluang yang akan dialami.
\end{abstract}

Kata Kunci : Analysis, Mutasi, Kinerja, dan SWOT

\section{PENDAHULUAN}

\section{International}

Organization (IMO) adalah organisasi dibawah PBB yang membidangi tentang pelayaran. Segala hal terkait industri maritim termasuk tentang Sumber Daya Manusia yang terlibat didalamnya diatur secara tegas dan lugas didalam seluruh konvensi/guide line/Resolusi yang dicetuskan oleh IMO. Berbagai SDM yang terkait dengan dunia maritim antara lain adalah Pelaut, Designated Person Ashore (DPA), Auditor, Company Security Officer (CSO), competent person untuk penanganan muatan berbahaya di area pelabuhan, marine pilot dan mooring personil.

Pelaut adalah setiap orang yang mempunyai kualifikasi keahlian atau keterampilan sebagai awak kapal (Peraturan Pemerintah Republik Indonesia Nomor 7 Tahun 2000 Tentang Kepelautan). Bukan hal yang mudah apabila seseorang ingin bekerja menjadi seorang pelaut di atas kapal, sebab mereka dituntut untuk memiliki Certificate Of Competency (COC) sesuai dengan jabatan seorang pelaut tersebut diatas kapal, ukuran kapal tempat pelaut tersebut bekerja serta lokasi/daerah pelayaran dari kapal yang akan mereka awaki. Selain itu seorang pelaut juga harus memiliki Certificate OfProficiency (COP) sesuai dengan jenis dan tipe kapal yang mereka awaki. Persyaratan lain untuk menjadi seorang pelaut adalah jaminan kesehatan jasmani dan rohani, yang dibuktikan dengan kepemilikan sertifikat kesehatan. Berbagai hak dan kewajiban seorang pelaut dituangkan secara terperinci ke dalam suatu perjanjian kerja laut. Perjanjian kerja laut dinyatakan syah apabila telah ditanda tangani oleh pihak pemilik kapal dan pelaut yang bersangkutan, proses selanjutnya yaitu proses pengesahan dokumen perjanjian kerja laut oleh syahbandar. Syahbandar adalah pejabat pemerintah di pelabuhan yang diangkat oleh Menteri dan memiliki kewenangan tertinggi untuk menjalankan 
dan melakukan pengawasan terhadap dipenuhinya ketentuan peraturan perundang- undangan untuk menjamin keselamatan dan keamanan pelayaran (Undang-undang Republik Indonesia Nomor 17 Tahun 2008 Tentang Pelayaran, 2008).

Hal-hal yang tertulis didalam Perjanjian kerja laut (PKL) antara lain meliputi identitas pelaut yang akan menandatangani PKL tersebut, jabatan pelaut tersebut diatas kapal, periode kontrak kerja pelaut, honorarium yang telah disepakati antara pelaut dengan pihak pemilik kapal, periode berlakunya PKL tersebut, lokasi dan tanggal perjanjian dibuat, hal-hal terkait pemutusan kontrak kerja, serta tanda tangan pelaut, pihak pemilik kapal dan pejabat syahbandar yang berwewenang. Seorang pelaut yang handal dituntut untuk selalu menjaga profesionalismenya , termasuk dalam kemampuannya untuk menyelesaikan masa kontrak sesuai dengan yang telah disepakati dalam PKL. Ketika seorang pelaut telah menyelesaikan masa kontrak kerjanya, maka pelaut tersebut berhak mendapatkan mutasi off untuk turun dari kapal sehingga pelaut tersebut bersifat nonaktif dari pekerjaan diatas kapal. Proses mutasi off yang dialami oleh seorang pelaut, bersamaan dengan proses mutasi on bagi pelaut yang lain dengan jabatan yang sama yang akan menggantikan kedudukannya diatas kapal.

Berdasarkan studi yang dilakukan terhadap pelaut yang berlayar di perusahaan dalam negeri, ditemukan bahwa sebagian pelaut mengeluhkan pernah mengalami over contract. Hal tersebut berarti bahwa pelaut tersebut masih dituntut untuk bekerja diatas kapal setelah periode kontrak kerja yang tercantum dalam PKL yang telah disepakatinya habis. Bagi seorang pelaut kontrak kerja yang relatif lama tentu menimbulkan rasa jenuh terlebih pekerjaan yang dilakukan bersifat monoton dan berkesinambungan. Terbatasnya fasilitas komunikasi dan hiburan di atas kapal menjadikan pekerjaan sebagai pelaut riskan dengan stress kerja, dimana hal-hal tersebut tentu akan mempengaruhi kondisi psikologi seorang pelaut yang akhirnya akan berpengaruh terhadap kinerja yang mereka hasilkan. Berdasarkan latar belakang tersebut, maka kami terdorong untuk melakukan analisa tentang dampak keterlambatan mutasi kerja pelaut terhadap kinerja pelaut tersebut.

\section{LANDASAN TEORI Mutasi Pelaut}

Mutasi adalah proses perpindahan pegawai baik secara vertikal maupun horizontal yang memiliki tujuan untuk menjaga efektifitas dan produktifitas kinerja karyawan (Raeka Novrita ; Adrie Frans Assa, 2015). Proses mutasi lazim dilakukan baik pada lingkungan perusahaan maupun non perusahan termasuk lingkup organisasi. Proses mutasi meliputi dua jenis, yaitu tour of area, yaitu proses perpindahan karyawan dari satu tempat ke tempat yang lain dengan menduduki jabatan yang sama, sedangkan tour of duty adalah proses perpindahan karyawan dari satu jabatan ke jabatan lain dalam satu unit kerja ( Suyati; Erni Yuningsih , 2016 ; Patricia Runtuwewe, Bernhard Tewal, Christoffel Mintardjo, 2016). Mutasi merupakan suatu tindak lanjut dari dilakukannya proses penilaian prestasi kerja seorang karyawan ( Ela Suparinah, 2018). Mutasi Karyawan merupakan salah satu bagian dari proses pengembangan Sumber Daya Manusia di lingkungan perusahaan maupun organisasi ( Patricia Runtuwewe, Bernhard Tewal, Christoffel Mintardjo, 2016). Dressel dalam Herry kurniawan; Tettet Fijrijanti; Cahya Irawadi, (2020) menyatakan bahwa mutasi merupakan suatu perpindahan karyawan dari satu pekerjaan ke pekerjaan lain tanpa adanya perubahan golongan maupun gaji.

Mutasi bagi seorang pelaut meliputi 2 jenis, yaitu Mutasi On dan Mutasi Off. Mutasi $O n$ adalah proses mutasi ketika seorang pelaut telah menyeleseaikan berbagai persyaratan administrasi dan dinyatakan siap secara lahir dan batin untuk naik ke atas kapal, dan bekerja dengan 
durasi waktu sesuai dengan yang tercantum di dalam PKL. Mutasi off adalah proses mutasi pelaut untuk cuti atau resign dari kapal dikarenakan telah menyelesaikan masa PKL sesuai dengan periode waktu yang telah disepakati antara pelaut tersebut dengan pemilik kapal. Mutasi dilakukan dengan tujuan agar karyawan memiliki kepuasan kerja sehingga mampu berprestasi maksimal di lingkungan organisasinya (Sastrohadiwiryo dalam Arine Herliza Rusadi; Sri Nuringwahyu; Daris Zunaida, 2020). Hal tersebut berarti ketepatan waktu proses Mutasi On dan mutasi off pada pelaut akan berpengaruh terhadap kinerja pelaut yang akan berdampak pada proses kemajuan organisasi di kapal tersebut.

\section{Kinerja Pelaut}

Faktor pendukung yang menjamin keberlangsungan suatu organisasi adalah prestasi dan kinerja pegawai (Suyati; Erni Yuningsih , 2016). Muheriono dalam N.D.Sabar., Adolfina., L.O.H. Dotulong (2017) mengemukakan bahwa kinerja merupakan pencapaian dari pelaksanan strategis dalam mewujudkan visi dan misi suatu organisasi. Kinerja dapat berupa barang maupun jasa yang dilakukan karyawan melalui kecakapan, kemampuan, pengetahuan, dan pengalaman yang dimilikinya (Arine Herliza Rusadi; Sri Nuringwahyu; Daris Zunaida, 2020). Basri dalam Patricia R (2016) menyatakan bahwa tingkat keberhasilan kinerja seseorang meliputi kemampuan dalam melaksanakan tugas yang meliputi standar hasil kerja, target, sasaran serta kriteria yang telah ditentukan dalam organisasi. Beberapa hal yang dapat menjadi indikator dalam pengukuran kinerja antara lain adalah kualitas yang merupakan hasil dari pekerjaan yang dihasilkan, baik berupa mutu atau kerapian maupun tingkat kesalahan yang timbul, kuantitas yang meliputi jumlah pekerjaan yang dapat diselesaikan, serta ketepatan waktu dalam menyelesaikan pekerjaan (Herry kurniawan; Tettet Fijrijanti; Cahya Irawadi, 2020).
Kinerja seorang pelaut diukur dan dinilai oleh setiap kepala department di kapal tempatnya bekerja. Penilaian kinerja bagi seorang pelaut yang bekerja sebagai tim deck department, akan dilakukan oleh seorang chief officer di kapal tersebut. Sedangkan pelaut yang bekerja dalam time engine department akan menerima penilaian kinerja yang dilakukan oleh Chief Engineer. Khusus untuk pelaut yang bekerja di bagian catering department, maka penilaian akan dilakukan oleh Chief Cook. Khusus untuk masing-masing kepala department, proses penilaian kinerja diberikan oleh Nakhoda kapal tersebut. Proses penilain kinerja seorang pelaut dilaksanakan disetiap akhir masa kontrak yang tercantum dalam perjanjian kerja laut (PKL).

\section{METODE}

Dalam melakukan analisa terhadap dampak keterlambatan Mutasi On dan Mutasi Off terhadap kinerja pelaut digunakan media SWOT Analysis. SWOT Analisis merupakan metode yang digunakan untuk menganalisa kekuatan, kelemahan, peluang dan ancaman dalam suatu spekulasi bisnis ( Fajar Nur'aini, 2019). Selanjutnya Fajar menjelaskan tentang empat faktor yang akan menjadi indikator untuk melakukan analisa dengan metode SWOT Analysis, antara lain meliputi strenghts (kekuatan), Weakness (kelemahan), Opportunities (peluang) dan Threats (ancaman). Stengths (kekuatan) adalah segala sesuatu yang menjadi suatu keunggulan. Weakness (kelemahan) merupakan segala sesuatu yang merupakan kekurangan, Opportunities (peluang) ialah segala sesuatu yang bersifat menguntungkan dan berasal dari luar organisasi dan Threats (ancaman) yaitu segala seauatu yang dapat menjadi pengganggu dalam kegiatan yang telah dilakukan.

SWOT Analysis dapat digunakan menjadi suatu metode riset. Riset SWOT diperlukan untuk membuat suatu organisasi menjadi lebih baik sesuai dengan visi serta 
misi organisasi tersebut (F. Rangkuti, 2019). Tujuan dari riset SWOT menurut Rangkuti (2019) adalah untuk mengetahui kondisi Internal dan eksternal suatu organisasi/kegiatan. Analisa pada kondisi internal bertujuan untuk untuk mengetahui faktor -faktor yang menjadi kekuatan dan kelemahan organisasi/kegiatan. Sedangkan kondisi eksternal, bertujuan agar mengetahui faktor-faktor yang menjadi peluang dan hambatan dalam organisasi atau kegiatan tersebut.
HASIL DAN PEMBAHASAN

Melalui SWOT Analysis, analisa dapat dilakukan terhadap dua permasalahan, yaitu analisa terhadap keterlambatan proses Mutasi On dan Mutasi off bagi pelaut, serta analisa terhadap dampak terhadap kinerja pelaut apabila proses Mutasi On dan Mutasi off mengalami ketidaktepatan dalam waktu pelaksanaan. Adapun SWOT Analisis tersebut dapat dijabarkan kedalam kondisi sebagai berikut :

\begin{tabular}{|c|c|}
\hline $\begin{array}{l}\text { STRENGTHS } \\
\end{array}$ & WEAKNESS \\
\hline $\begin{array}{l}\text { 1. Pelaut menerima gaji tambahan selama } \\
\text { mengalami proses keterlambatan } \\
\text { Mutasi Off. } \\
\text { 2. Pengetahuan Pelaut tentang bidang } \\
\text { pekerjaan yang menjadi tanggung } \\
\text { jawabnya dikapal tersebut akan lebih } \\
\text { baik sebab dilaksnakan secara } \\
\text { berkesinambungan dalam periode } \\
\text { waktu yang relatif lebih lama. }\end{array}$ & $\begin{array}{l}\text { 1. Pelaut yang mengalami over contract } \\
\text { mengalami kejenuhan } \\
\text { 2. Pelaut yang mengalami over contract } \\
\text { mengalami penurunan semangat } \\
\text { kerja sebagai dampak dari kejenuhan } \\
\text { 3. Pelaut yang mengalami over contract } \\
\text { mengalami penurunan produktifitas } \\
\text { kinerja sebagai dampak dari } \\
\text { penurunan semangat kerja } \\
\text { 4. Pelaut yang mengalami over contract } \\
\text { akan merasa terbebani sehingga akan } \\
\text { mengalami hambatan dalam berkarir. }\end{array}$ \\
\hline OPPORTUNITIES & THREATS \\
\hline $\begin{array}{l}\text { 1. Kinerja pelaut sangat } \\
\text { mempengaruhi kinerja perusahaan, } \\
\text { sehingga akan berpengaruh terhadap } \\
\text { kepercayaan stakeholders. }\end{array}$ & 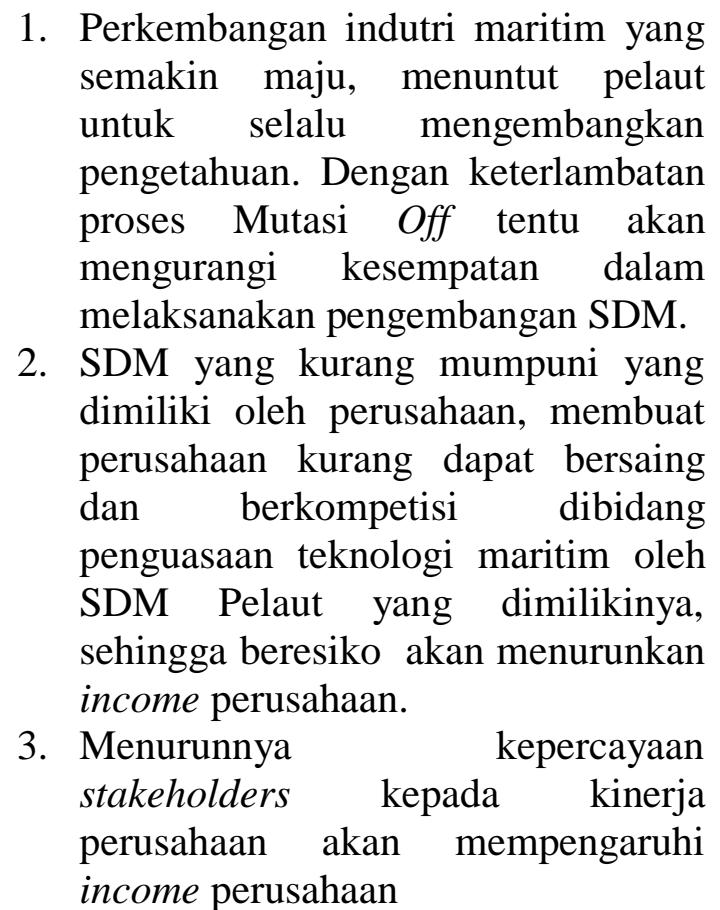 \\
\hline
\end{tabular}


Dari SWOT Analysis yang dilakukan mengenai permasalahan tersebut diatas dapat diketahui jika keterlambatan proses Mutasi Off pelaut akan berpengaruh terhadap kinerja pelaut yang secara langsung akan mempengaruhi kinerja perusahaan yang akan berimbas pada kepercayaan stakeholders terhadap kemampuan perusahaan. Analisa SWOT tersebut memnunjukkan bahwa terdapat 2 strengths (kekuatan), 4 weakness (kelemahan), 1 Opportunities (tantangan), dan 3 Threats (hambatan).

\section{KESIMPULAN}

Dari proses analisa yang dilakukan dapat diketahui jika kelemahan dan hambatan yang bersifat merugikan perusahaan serta akan dialami oleh perusahaan tersebut jika melakukan keterlambatan Mutasi Off pelaut relatif lebih banyak daripada kekuatan dan tantangan/peluang yang bersifat menguntungkan perusahaan. Hal tersebut berarti kerugian yang akan dialami oleh perusahaan dari imbas keterlambatan proses Mutasi Off pelaut disetiap armadanya jauh lebih besar dibandingkan dengan keuntungan yang akan didapatkan dari perusahaan tersebut.

Penelitian selanjutnya yang kami harapkan dapat dilakukan untuk mendalami permasalahn tersebut adalah melakukan analisa lanjutan dengan pendekatan Balanced score card yang berfungsi untuk melakukan pengukuran kinerja pelaut yang mengalami over contract, sehingga hasil yang didapatkan dapat menjadi formulasi strategis hingga implementasi operasional bagi setiap pelaut pada setiap perusahaan.

\section{DAFTAR PUSTAKA}

Kurniawan Herry dkk. 2020. Pengaruh Mutasi, Motivasi dan Kompetensi Terhadap Kinerja Auditor. SIKAP Volume 4 No. 2. Halaman 98-106

Nur'aini Fajar .2019. The Guide Book Of SWOT.Quadrant: Yogyakarta
Rangkuti Freddy. 2019.SWOT Balanced Scorecard. PT Gramedia Pustaka Utama :Jakarta.

Runtuwewe Patricia dkk. 2016. Pengaruh Penempatan Kerja, Mutasi dan beban kerja terhadap Kinerja Karyawan Pada PT. Bank Sulutgo Manado. Jurnal Berkala Ilmiah Efisiensi Volume 16 No. 01. Halaman 269279.

Rusadi Herliza Arine dkk, 2020. Pengaruh Mutasi dan Promosi Jabatan Terhadap Kinerja Karyawan.JIAGABI, Vol 9No.2. Halaman 112-117

Suyati., Erni Yuningsih. 2016. Pengaruh Mutasi dan Promosi Jabatan Terhadap Kinerja Pegawai di Pusat Pelatihan Manajemen dan Kepemimpinan Pertanian (PPMKP) Ciawi-Bogor. Jurnal Visioner Volume 2 No. 1. Halaman 51- 60

Suparinah Ela. 2018. Pengaruh Mutasi dan Promosi Jabatan Terhadap Kinerja Karyawan Pada PT. Waru Kaltim Plantation Di Penajam Paser Utara.eJurnal administrasi Bisnis/ Volume 6 No.2. Halaman 425-438. 